not shown) or PBO $+52(n=51)$ for 52 wks based on reported data, including all responders as well as patients with post-escape data following flare.

Results: Improvements in SF-36 PCS and MCS scores, 6 of 8 SF-36 domains, and FACIT-Fatigue at wk 52 were significantly greater with weekly TCZ vs PBO $+52(p<0.01)$ (table 1, figure 1). At wk 52, mean scores met or exceeded age/gender (A/G)-matched normative scores in the weekly TCZ group; higher proportions of patients reported scores exceeding A/G norms in SF-36 PCS and MCS, all SF-36 domains, and FACIT-Fatigue (Table) compared with PBO groups. The median cumulative prednisone dose over 52 wks was lower with weekly. TCZ $(18620 \mathrm{mg})$ vs PBO +26 (3296.0 mg) or PBO +52 (3817.5 mg) $(\mathrm{p}<0.01)$.

Table. Change From Baseline to Wk 52; mean score (\% $\geq A / G$ norms)

\begin{tabular}{|c|c|c|c|c|c|c|}
\hline & \multicolumn{3}{|c|}{$\begin{array}{c}\text { Weekly TCZ+26 } \\
n=100\end{array}$} & \multicolumn{3}{|c|}{$\begin{array}{c}\text { PBO+52 } \\
n=51\end{array}$} \\
\hline & Baseline & Wk 52 & LSM $\Delta$ & Baseline & Wk 52 & $\begin{array}{c}\text { LSM } \\
\Delta\end{array}$ \\
\hline \multicolumn{7}{|l|}{ PROs (A/G norms) } \\
\hline PtGA & 43.61 & 24.36 & -17.14 & 47.78 & 35.44 & -7.56 \\
\hline FACIT-Fatigue (40.0) & $\begin{array}{l}36.05 \\
(43.4)\end{array}$ & $\begin{array}{l}42.08 \\
(73.8)\end{array}$ & $5.30^{\mathrm{a}}$ & $\begin{array}{l}31.42 \\
(32.7)\end{array}$ & $\begin{array}{l}32.62 \\
(35.6)\end{array}$ & -0.42 \\
\hline $\begin{array}{l}\text { SF-36 PCS } \\
(50.0)\end{array}$ & $\begin{array}{l}43.10 \\
(23.7)\end{array}$ & $\begin{array}{l}47.75 \\
(43.5)\end{array}$ & $4.18^{a}$ & $\begin{array}{l}41.12 \\
(20.4)\end{array}$ & $\begin{array}{l}41.24 \\
(22.2)\end{array}$ & -0.40 \\
\hline SF-36 MCS (50.0) & $\begin{array}{l}42.77 \\
(33.0)\end{array}$ & $\begin{array}{l}51.64 \\
(60.0)\end{array}$ & $8.10^{\mathrm{a}}$ & $\begin{array}{l}40.45 \\
(34.7)\end{array}$ & $\begin{array}{l}44.86 \\
(40.0)\end{array}$ & 1.89 \\
\hline \multicolumn{7}{|c|}{ SF-36 Domains (A/G norms) } \\
\hline $\begin{array}{l}\text { Physical function } \\
(67.56)\end{array}$ & $\begin{array}{l}69.10 \\
(60.0)\end{array}$ & $\begin{array}{l}78.28 \\
(78.8)\end{array}$ & 6.83 & $\begin{array}{l}59.40 \\
(42.0)\end{array}$ & $\begin{array}{l}65.44 \\
(55.6)\end{array}$ & 2.68 \\
\hline Role physical (69.44) & $\begin{array}{l}49.56 \\
(25.0)\end{array}$ & $\begin{array}{l}73.75 \\
(56.5)\end{array}$ & $20.64^{a}$ & $\begin{array}{l}45.38 \\
(28.0)\end{array}$ & $\begin{array}{l}53.89 \\
(33.3)\end{array}$ & 4.46 \\
\hline Bodily pain (64.52) & $\begin{array}{l}61.93 \\
(41.0)\end{array}$ & $\begin{array}{l}73.25 \\
(65.9)\end{array}$ & $10.89^{a}$ & $\begin{array}{l}55.67 \\
(34.7)\end{array}$ & $\begin{array}{l}56.27 \\
(31.1)\end{array}$ & -2.87 \\
\hline $\begin{array}{l}\text { General health } \\
(66.49)\end{array}$ & $\begin{array}{l}55.00 \\
(25.8)\end{array}$ & $\begin{array}{l}65.81 \\
(57.6)\end{array}$ & $9.06^{\mathrm{a}}$ & $\begin{array}{l}55.69 \\
(36.0)\end{array}$ & $\begin{array}{l}52.29 \\
(22.0)\end{array}$ & -4.05 \\
\hline $\begin{array}{l}\text { Vitality } \\
(58.65)\end{array}$ & $\begin{array}{l}50.19 \\
(33.3)\end{array}$ & $\begin{array}{l}66.13 \\
(68.2)\end{array}$ & $15.69^{\mathrm{a}}$ & $\begin{array}{l}42.38 \\
(28.0)\end{array}$ & $\begin{array}{l}49.17 \\
(33.3)\end{array}$ & 3.53 \\
\hline $\begin{array}{l}\text { Social function } \\
(81.49)\end{array}$ & $\begin{array}{l}64.25 \\
(29.0)\end{array}$ & $\begin{array}{l}84.71 \\
(63.5)\end{array}$ & $17.35^{\mathrm{a}}$ & $\begin{array}{l}63.00 \\
(40.0)\end{array}$ & $\begin{array}{c}67.50 \\
40.0\end{array}$ & 2.34 \\
\hline $\begin{array}{l}\text { Role emotional } \\
(82.08)\end{array}$ & $\begin{array}{l}66.38 \\
(43.0)\end{array}$ & $\begin{array}{l}82.45 \\
(62.4)\end{array}$ & 13.37 & $\begin{array}{l}60.33 \\
(36.0)\end{array}$ & $\begin{array}{l}69.63 \\
(46.7)\end{array}$ & 3.53 \\
\hline Mental health (77.16) & $\begin{array}{l}64.04 \\
(32.3)\end{array}$ & $\begin{array}{l}77.94 \\
(52.9)\end{array}$ & $12.54^{\mathrm{a}}$ & $\begin{array}{l}59.10 \\
(24.0)\end{array}$ & $\begin{array}{l}66.33 \\
(31.1)\end{array}$ & 3.13 \\
\hline
\end{tabular}

LSM $\Delta$, least squares mean change from baseline to wk 52; PtGA, patient-reported global assessment.

All analyses based on observed data (post-escape data included)

${ }^{\mathrm{a}} p<0.01$ vs $\mathrm{PBO}+52$.

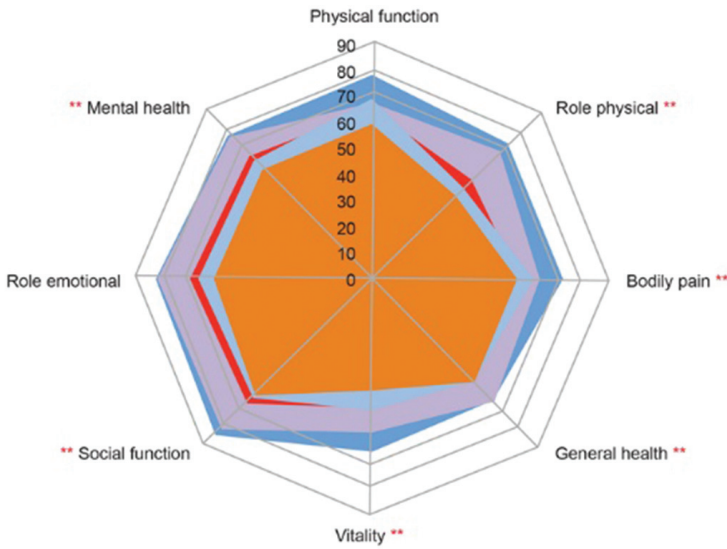

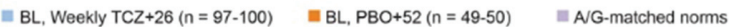
Wk 52 , Weekly TCZ $+26(n=85)$

Wk $52, \mathrm{PBO}+52(\mathrm{n}=45)$

${ }^{*} p<0.01 \mathrm{vs} \mathrm{PBO}+52$.

AVG, age/gender; BL, baseline.

Abstract SAT0550 - Figure 1. SF-36 Domains at BL and Week 52. ${ }^{* *} \mathrm{p}<0.01$ vs $\mathrm{PBO}+52$. $\mathrm{A} / \mathrm{G}$, age/gender; $\mathrm{BL}$, baseline.

Conclusions: Patients with GCA treated with weekly TCZ $162 \mathrm{mg}$ and a 26-wk GC taper reported statistically significantly greater improvements in health-related quality of life and fatigue that exceeded normative values compared with those receiving 52-wk GC taper alone, in part ascribed to lower steroid doses.
REFERENCE:

[1] Stone JH, et al. N Engl J Med 2017;377:317-328.

Disclosure of Interest: V. Strand Consultant for: AbbVie, Amgen, AstraZeneca, BMS, Boehringer Ingelheim, Celgene, Celltrion, CORRONA, Crescendo, EMD Serono, Genentech/Roche, GSK, Janssen, Lily, Merck, Novartis, Pfizer, Protagen, Regeneron, Samsung, Sandoz, Sanofi, UCB, S. Dimonaco Employee of: Roche, K. Tuckwell Shareholder of: Roche, Employee of: Roche, M. Klearman Employee of: Genentech, N. Collinson Employee of: Roche, J. H. Stone Grant/ research support from: Roche, Genentech, Xencor, Consultant for: Roche, Genentech, Xencor

DOI: 10.1136/annrheumdis-2018-eular.2616

\section{SAT0551 LEG ULCERS IN BEHCET'S SYNDROME: AN OBSERVATIONAL SURVEY IN 24 PATIENTS}

Y. Ozguler ${ }^{1}$, Z. Kutlubay ${ }^{2}$, A.S. Dikici ${ }^{3}$, M. Melikoglu' ${ }^{1}$, C. Mat ${ }^{2}$, H. YazıcI ${ }^{1}$

E. Seyahi ${ }^{1} .{ }^{1}$ Department of Internal Medicine, Division of Rheumatology;

${ }^{2}$ Department of Dermatology, ${ }^{3}$ Department of Radiology, Istanbul University

Cerrahpasa Medical Faculty, İstanbul, Turkey

Background: Formal experience with leg ulcers in Behçet's syndrome (BS) is limited. It is a rare complication that can be seen during the course of mainly pts with the post-thrombotic syndrome. They can be difficult to manage and may cause disability leading to unemployment and severe impairment in quality of life.

Objectives: In this observational survey, we aimed to describe clinical characteristics of pts with leg ulcers.

Methods: A total of $24 \mathrm{pts}(23 \mathrm{M} / 1 \mathrm{~F})$ that were seen at our multidisciplinary BS clinic between May 2016-Jan 2018 were evaluated with the help of a standardised questionnaire. Venous Doppler US and if necessary abdominal CT were used to evaluate localization of venous involvement. Biopsies were done if needed. Medical and other interventional treatments were recorded.

Results: The mean age at disease onset was $27.5 \pm 7.1$ years. The median duration between the disease onset and ulcer development was 4.0 [2.5-11.5] years The median follow-up was 7.8 [IQR: 2.9-14.2] years. Eleven (46\%) were unemployed due to the leg ulcer. Venous involvement was present in 20 pts (83\%). Lower extremity vein thrombosis was shown in all these $20 \mathrm{pts}$. It was mostly bilateral (15/20). Femoral veins were the most commonly involved (18/20), followed by popliteal veins $(14 / 20)$, v. saphena magna or v. saphena parva $(7 / 20)$, iliac veins or inferior vena cava $(8 / 20)$. The same $9 / 20$ pts had other large vessel involvement such as pulmonary artery $(n=5)$ or dural sinus thrombosis $(n=3)$. Four pts did not have any venous thrombosis or insufficiency. Histopathologic studies could be done in 3 and showed necrotizing vasculitis in 2 and venous stasis in the 3 rd. Twelve pts $(50 \%)$ had solitary ulcers and 12 had 2 or more. We observed a total of 34 ulcers in 24 pts. They were mostly found around the medial malleolus (15/34) and anterior surface of the tibia (14/34). Five pts had leg ulcers at unusual places such as lateral malleolus $(n=2)$, popliteal fossa $(n=1)$ and posterior surface of the tibia $(n=2)$. Immunosuppressive agents including azathioprine, cyclophosphamide, interferon alpha, infliximab, and corticosteroids were used. Bed rest was advised to almost all. lloprost infusions were given in $13(54 \%)$ for a median duration of 6 mo. Additionally, larvae of Lucilia sericata were tried in 9 pts. Skin graft insertion was used in $2 \mathrm{pts}$, however, was successful in 1 . We observed that in 11 (46\%) pts 17 ulcers healed in median 24 mo [IQR:9-78]. In the remaining 13 (54\%) pts 17 ulcers stayed as unhealed for a median 7 years [IQR:5-11], despite all interventions and medical treatment. We saw the mean age at BS onset was significantly younger $(24.4 \pm 5.4$ vs $30.4 \pm 7.3$ years; $p<0.05)$ and the median time between disease onset and ulcer development was significantly shorter ( 3 [IQR:1-4.5] vs 10 [IQR:4-14 years, $p<0.05]$ in pts with healed ulcers compared to those with unhealed ulcers. There were no apparent associations with the type of management and the severity of venous involvement. 


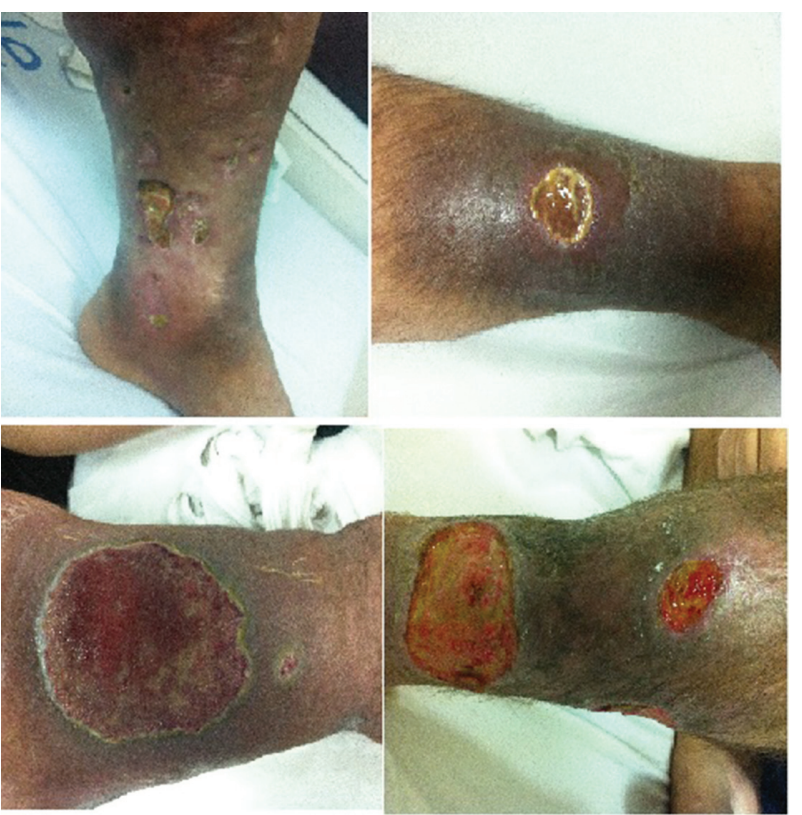

Conclusions: Leg ulcer develops mainly due to venous disease in the lower extremities. Peripheral arterial occlusive disease seems to be rarely involved. It may cause unemployment in $46 \%$ and be resistant to treatment in $54 \%$ of the cases. Ulcers that appear early during the disease course heal faster and is more responsive to treatment.

Disclosure of Interest: None declared

DOI: 10.1136/annrheumdis-2018-eular.6510

SATURDAY, 16 JUNE 2018

\section{Osteoarthritis}

\section{SAT0552 BASELINE PREDICTORS OF UPPER LEG MUSCLE STRENGTH OVER 2 AND 4 YEARS IN SUBJECTS WITH KNEE OSTEOARTHRITIS:DATA FROM THE OSTEOARTHRITIS INITIATIVE}

A.H. De Zwart ${ }^{1}$, M. van der Leeden ${ }^{1,2}$, L.D. Roorda ${ }^{1}$, M. van der Esch ${ }^{1}$, J.W. R. Twisk ${ }^{3}$, W.F. Lems ${ }^{1,4,5}$, J. Dekker ${ }^{2,6} .{ }^{1}$ Reade Rehabilitation Center Amsterdam; ${ }^{2}$ Dept of Rehabilitation Medicine, VU University Medical Center (VUmc), Amsterdam Public Health research institute; ${ }^{3}$ Department of Epidemiology and Biostatistics, VU University Medical Center, VU University; ${ }^{4}$ Dept of Rheumatology, VU University Medical Center (VUmc); ${ }^{5}$ Jan van Breemen Research Institute; ${ }^{6}$ Dept of Psychiatry, VU University Medical Center, VU University, Amsterdam, Netherlands

Background: Muscle weakness is common in patients with knee osteoarthritis (OA). Muscle weakness negatively impacts future functional status, and has been linked to symptomatic and radiographic progression of knee OA. Limited information is available on the course of muscle strength over time in these patients.

Objectives: The aim of the present study is to (i) analyse the course and (ii) to identify baseline predictors for upper leg muscle strength over time in subjects with knee OA.

Methods: Data were obtained from the progression cohort of the Osteoarthritis Initiative (OAI) database. Upper leg muscle strength (in $\mathrm{N} / \mathrm{kg}$ ) was measured at baseline, 24 months and 48 months. Potential baseline predictors were demographical factors (age, gender, race, body height, body weight), metabolic factors (body mass index (BMI)), nutrition and vitamin related factors (dietary protein intake, dietary energy intake, vitamin D use, glucosamine use), lifestyle related factors (alcohol consumption, smoking, physical activity), OA-specific factors (KL grade, knee alignment, effusion, pain, pain medication use) and health related factors (comorbidities and depression). Univariable and multivariable mixed model analyses were performed to analyse the course and to identify baseline predictors for muscle strength over time.

Results: A total of 1390 subjects with knee osteoarthritis were included. The majority of the subjects were female $(57.1 \%)$, mean \pm SD for age was 61.4 \pm 9.1 and mean $\pm S D$ for body mass index was $30.2 \pm 4$.9. All subjects had frequent knee symptoms and radiographic tibiofemoral knee OA (Kellgren en Lawrence score $\geq 2$ ) at baseline. Muscle strength was significantly lower at 24 months and 48 months compared to baseline; there was no difference between 24 and 48 months. Older age, being female, higher BMI, being non-Caucasian, lower protein intake ( $\mathrm{g} / \mathrm{kg}$ bodyweight), higher dietary energy intake, alcohol consumption, less physical activity valgus malalignment, higher score on the WOMAC pain subscale and the use of pain medication at baseline were predictors of lower muscle strength over time.

Conclusions: Muscle strength decreased over time between baseline and 24 months, but not between 24 and 48 months, which may be attributed to reaching a plateau or to other reasons. In the present study a number of demographic factors, metabolic factors and factors related to nutrition and vitamins, lifestyle and knee OA were found to be predictive for decreased muscle strength over time. This set of baseline factors can be used to identify patients with knee OA at risk for decline of muscle strength over time. External validation of our model is needed.

Disclosure of Interest: None declared

DOI: 10.1136/annrheumdis-2018-eular.6466

\section{SAT0553 CHONDROCALCINOSIS OF THE KNEE AND THE RISK FOR KNEE OR HIP OSTEOARTHRITIS PROGRESSION DATA FROM THE KHOALA COHORT}

A. Latourte ${ }^{1,2}$, A.C. Rat ${ }^{3,4}$, W. Ngueyon Sime $^{3}$, C. Roux ${ }^{5}$, F. Guillemin ${ }^{3}$, P. Richette ${ }^{1,2}$. ${ }^{1}$ Rheumatology Department, Lariboisière Hospital, Assistance Publique-Hôpitaux de Paris; ${ }^{2}$ Inserm U1132, Paris Diderot University, Paris; ${ }^{3}$ Inserm CIC 1433 Epidemiologie Clinique, Université de Lorraine; ${ }^{4}$ Rheumatology Department, CHRU Nancy, Nancy, ${ }^{5}$ Rheumatology Department, CHU Pasteur 2, Lamhess EA6309, UMR7277 iBV CNRS, University of Nice Sophia Antipolis, Nice, France

Background: Cross-sectional studies repeatedly found that chondrocalcinosis (CC) is associated with osteoarthritis (OA). However, whether CC worsens preexisting knee or hip OA is unclear.

Objectives: We conducted this study to assess the impact of knee CC on the risk of 1 ) incident joint replacement surgery, 2) worsening of pain or function and 3) radiographic progression in patients with symptomatic knee OA.

Methods: The KHOALA cohort is a French multicenter population-based cohort of 878 patients with symptomatic knee and/or hip OA (ACR criteria), aged 40-75 years. Patients were followed annually by self-reported questionnaires and by clinical examination and radiography at baseline (year 0), years 3 and 5 . Only patients with knee OA were kept for this analysis. CC, defined by the presence of calcium deposits within hyaline or fibro-cartilage on knee radiograph (anteroposterior view), was recorded as present or absent. We used Cox proportional-hazard regression modelling to estimate the local or systemic impact of $\mathrm{CC}$ at one knee (index knee) on the 5 year risk of incident total knee replacement (TKR) at the index knee or incident total hip or knee joint replacement (TJR), respectively. In the subgroup of patients without incident TJR during follow-up, logistic regression was performed to assess whether CC was associated with the worsening of Western Ontario and McMaster Universities Arthritis Index (WOMAC) for OA pain or function, or with radiographic progression as defined by a change in Kellgren and Lawrence $(\mathrm{KL})$ grade, between years 0 and 5 .

Results: Among the 656 patients included (mean \pm SD age $62.2 \pm 8.5$ years; $70.3 \%$ females), $93(14.2 \%)$ had CC in at least one knee at baseline. As compared with patients without $C C$, those with $C C$ were older $(64.3 \pm 9.6$ vs $61.9 \pm 8.2$ years; $\mathrm{p}=0.009)$, had longer disease duration $(16.4 \pm 10.5$ vs $13.0 \pm 7.6$ years; $p<0.001)$ and lower body mass index (29.1 \pm 5.3 vs $\left.30.5 \pm 6.3 \mathrm{~kg} / \mathrm{m}^{2} ; \mathrm{p}=0.047\right)$. Patients with/ without $C C$ did not differ in baseline pain $(7.1 \pm 4.3$ vs $6.6 \pm 3.8 ; p=0.26)$ and function (22.2 \pm 14.7 vs $20.7 \pm 13.5 ; p=0.32)$ scores, or $\mathrm{KL}$ grade $(\mathrm{p}=0.69)$. Overall, 105 $(16.0 \%)$ and 91 (13.9\%) patients underwent TJR and TKR of the index knee, respectively, during follow-up. The presence of $\mathrm{CC}$ at one knee did not affect the risk of TKR in the same index knee $(\mathrm{HR}=1.0 ; 95 \% \mathrm{Cl} 0.6$ to 1.8), or risk of TJR $(\mathrm{HR}=0.9 ; 95 \% \mathrm{Cl} 0.5$ to 1.6$)$. In patients without incident TJR surgery $(n=551)$, the presence of CC did not affect the risk of worsened WOMAC pain/function scores or $\mathrm{KL}$ grade at year 5 .

Conclusions: In a population-based cohort of symptomatic knee OA, the presence of $C C$ in the knee did not affect the risk of subsequent TKR or TJR, nor clinical or radiographic outcomes at 5 years. These results suggest that $C C$ is not a risk factor for worsening clinical or structural outcomes in knee OA.

Disclosure of Interest: None declared

DOI: 10.1136/annrheumdis-2018-eular.4700

\section{SAT0554 PREOPERATIVE PHYSICAL FUNCTION INFLUENCES ON STAIR CLIMBING ABILITY 1 MONTH AFTER TOTAL KNEE ARTHROPLASTY}

B.R. Kim. Jeju National University Hospital, Jeju, Korea, Republic Of

Objectives: This study was undertaken to identify preoperative physical performance factors predictive of stair climbing ability 1 month following total knee arthroplasty. 